\title{
Effect of probiotics in the treatment of acute noninflammatory diarrhea in hospitalized children aged
}

\section{2-10 years}

Abolfazl Khoshdel, Karam-Ali Kasiri, Simin Salehi ${ }^{1}$, Morteza Sedehi ${ }^{2}$

Departments of Pediatrics, ${ }^{2}$ Statistics, Shahrekord University of Medical Sciences, ${ }^{1}$ General Physician, Shahrekord University of Medical Sciences, Shahrekord, Iran

\section{Abstract}

Objective: Diarrhea is the second leading cause of death in children. Therefore, the aim of this study was to investigate the effect of probiotics in the treatment of acute noninflammatory diarrhea in children aged 2-10 years in the Pediatric Ward of Hajar Hospital in Shahrekord.

Methods: This clinical trial was performed on 184 children with diarrhea. Eighty-six children were randomly assigned to the KidiLact probiotic group and 87 ones to the control group. Patients' demographic information, symptoms, and other variables were recorded in a checklist. The data were analyzed by SPSS version 16 (Chicago, IL) using Chi-square and independent $t$-test.

Results: The mean frequency of diarrhea in the $2^{\text {nd }}$ and $4^{\text {th }}$ days $(P<0.001)$, duration of fever $(P=0.01)$, duration of diarrhea $(P<0.001)$, and duration of hospital stay $(P=0.001)$ were significantly lower in the probiotic group than those in the control group. The frequency of recovery in the $2^{\text {nd }}(P=0.013)$ and $4^{\text {th }}(P<0.001)$ days was significantly higher in the probiotic group than that in the control group. There was no significant difference in the frequency of dyspepsia between the patients of the two groups $(P=0.331)$. Conclusion: Probiotics are effective in the treatment of acute noninflammatory diarrhea in children aged $2-10$ years and can be used as a safe treatment alongside the standard treatment.

Keywords: Diarrhea, dietary supplements, fluid therapy

Address for correspondence: Dr. Karam-Ali Kasiri, Shahrekord University of Medical Sciences, Shahrekord, Iran.

E-mail: kasiri207@yahoo.com

\section{INTRODUCTION}

Diarrhea is the second leading cause of death in children under the age of 5 years in the world, and 1.7 million of the children develop it each year, 525,000 of whom die. ${ }^{[1]}$ In acute noninflammatory diarrhea in children, the small or large intestine may be affected, which is often caused by Shigella, Escherichia coli, Neuroviruses, Rotavirus, Giardia lamblia, Cryptosporidium parvum, and Entamoeba histolytica.

\begin{tabular}{|l|l|}
\hline \multicolumn{2}{|c|}{ Access this article online } \\
\hline Quick Response Code: & Website: \\
\hline & www.jpionline.org \\
\cline { 2 - 2 } & \\
\hline
\end{tabular}

Dehydration, fever, diarrhea, dysentery, and vomiting are common complications of the disease. ${ }^{[2,3]}$ Therefore, appropriate therapeutic measures are needed to improve the morbidity and reduce the mortality of these children. In the treatment of acute noninflammatory diarrhea in children, unnecessary interventions such as the administration of antibiotics should be avoided. This is because, in addition to eliminating intestinal microbiota,

This is an open access journal, and articles are distributed under the terms of the Creative Commons Attribution-NonCommercial-ShareAlike 4.0 License, which allows others to remix, tweak, and build upon the work non-commercially, as long as appropriate credit is given and the new creations are licensed under the identical terms.

For reprints contact: reprints@medknow.com

How to cite this article: Khoshdel A, Kasiri KA, Salehi S, Sedehi M. Effect of probiotics in the treatment of acute noninflammatory diarrhea in hospitalized children aged 2-10 years. Int J Pharma Investig 2018;8:200-4. 
they increase drug resistance. ${ }^{[3,4]}$ Being cost-effective, treatments should also have the least possible cost to the patient. ${ }^{[5]}$ Different treatments for this condition have been suggested, most important of which are fluid therapy, antipyretics, and if necessary, antiparasitic and antimicrobial drugs and probiotics. Probiotics are one of the treatments of choice for some infections. ${ }^{[6]}$ Probiotics are a product that contains viable and specific microorganisms in sufficient quantities to modify the microbial flora through localization or colonization in the host body, and thus produce beneficial health effects for the host. ${ }^{[7]}$ However, there are still a lot of ambiguous aspects about probiotic treatments for gastrointestinal problems and their dosage, safety, and efficacy which are being debated. ${ }^{[8]}$ Considering that childhood is a developmental stage and infectious diseases should not delay it, gastrointestinal microbiota should be at its normal level, and also due to antibiotic inactivity on viral pathogens that are among important causes of acute diarrhea in children, examination and identification of other treatments for controlling diarrhea and its complications seem to be necessary. ${ }^{[0]}$ Therefore, the present study was conducted to investigate the effect of probiotics in the treatment of children's diarrhea.

\section{METHODS}

This study was performed as a double-blind clinical trial on 174 children with noninflammatory acute diarrhea who referred to Hajar Hospital in Shahrekord, Southwestern Iran, between 2016 and 2017. The sample size was determined based on similar studies in this field and a sample size calculation formula. ${ }^{[10,11]}$ Finally, the patients were divided into two groups of 87 controls and 86 probiotics [Figure 1].

\section{Consort study}

The children were selected from among eligible ones in the study population by convenience sampling. Inclusion criteria included being a child, suffering from noninflammatory acute diarrhea, and providing consent to participate in the study. Fever above $38.5^{\circ} \mathrm{C}$, severe dehydration, diarrhea, severe malnutrition, recent use of
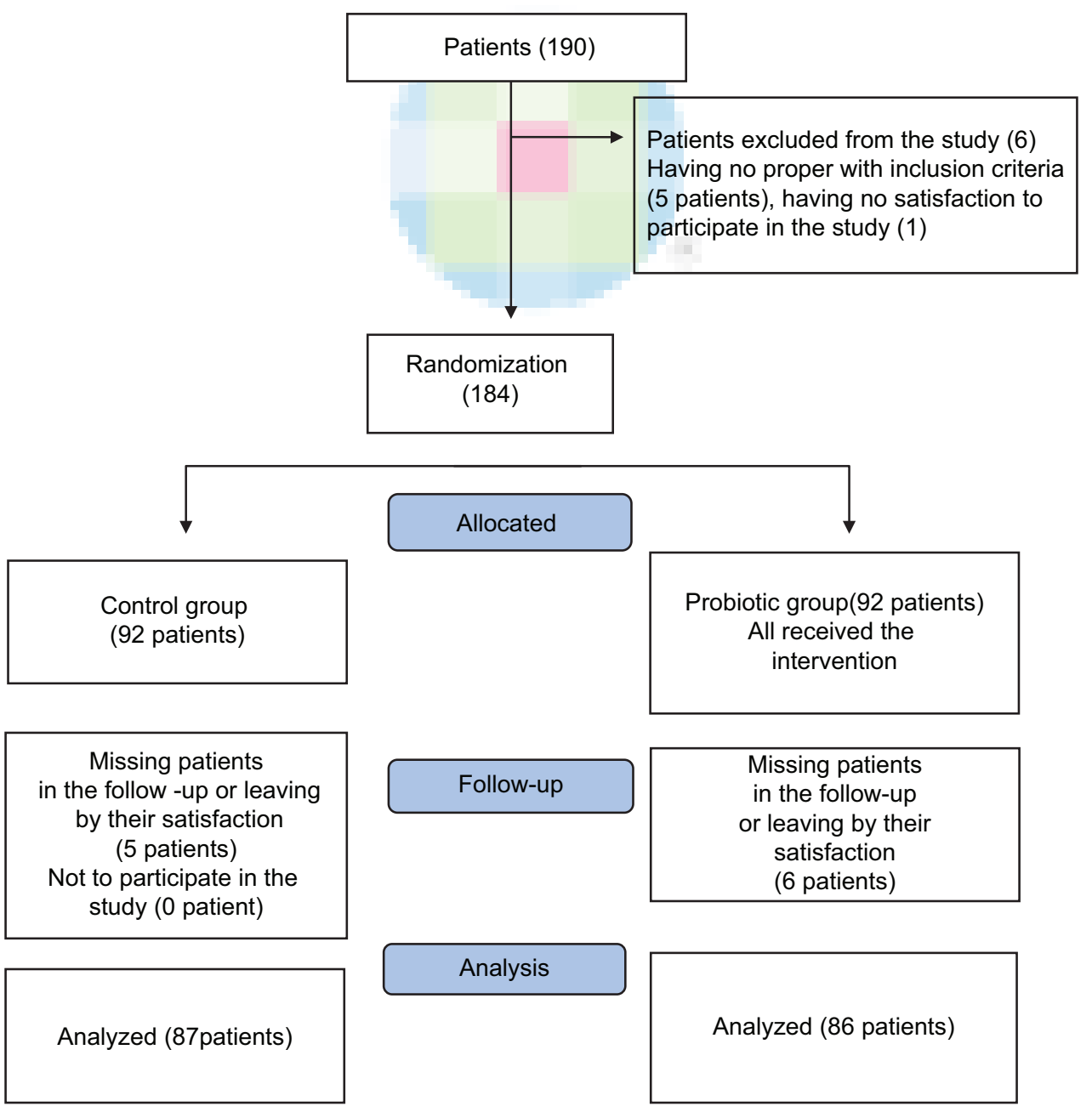

Figure 1: Frequency of samples in the probiotic and control groups 
antibiotics or anticoagulants, complications (not observed in our study), and immunodeficiency were considered exclusion criteria.

In this study, all the principles of the Helsinki Declarations were observed and the code of ethics by number of IR SKUMS. REC.1397.27 was obtained from Shahrekord University of Medical Sciences. Furthermore, the parents of all children provided informed consent for their children's participation in the study. The intervention group received probiotic treatment daily in a sachet of KidiLact, for up to 5 days if symptoms persisted and placebo was given to the control group.

For both groups, treatment protocol (fluid therapy) was also performed. ${ }^{[12]}$ Follow-up of the treatment procedure was performed daily by asking the mother about the persistence of diarrhea, the number of daily stools, the improvement of the child's appetite, and the fever by the researcher, and all information were recorded in the checklist for each child separately. In this study, the physician and the patient were blind to grouping, and the study was double-blind. KidiLact is a probiotic compound for children over the age of 2 years that contains high levels of seven beneficial bacterial strains, including the children-specific strain Bifidobacterium infantis, along with the fructooligosaccharide (contributing to the growth and activity of probiotics), and its formula has been specially developed for children so that they can use it easily. Other key ingredients are: B vitamins, maltodextrin, lactose, avocil, magnesium stearate, and talc. Probiotics in this product include Lactobacillus casei, Lactobacillus acidophilus, Lactobacillus rbamnosus, Lactobacillus bulgaricus, B. infantis, Bifidobacterium brevis, and Streptococcus thermophilus. All patients' information including demographic characteristics and paraclinical symptoms was recorded in the checklist. Data analysis was performed using Chi-square test and independent $t$-test to analyze qualitative data and compare the quantitative data of the two groups, respectively. Due to the absence of establishing primary assumptions such as normal distribution, the Mann-Whitney parametric test was used. All tests were performed at a significance level of $5 \%$.

\section{RESULTS}

Regarding gender, 93 (53.8\%) were male and 80 (46.2\%) were female, with no significant difference between the two groups $(P=0.707)$. The mean age of the participants was $5.78 \pm 1.96$ years. The mean and standard deviation of age were not significantly different between the two groups $(P=0.559)$.

In addition, the mean frequency of diarrhea on the $2^{\text {nd }}$ and $4^{\text {th }}$ day $(P<0.001)$, the mean duration of fever $(P=0.01)$, the mean duration of diarrhea $(P<0.001)$, and the duration of admission ( $P=0.001)$ were significantly less in the probiotic group than those in the control group [Table 1].

There was no significant difference in anorexia among the patients in both the groups $(P=0.331)$. On the other hand, the frequency of recovery on the $2^{\text {nd }}$ day was significantly higher in the probiotic group than that in the control group $(19.8 \%$ vs. $6.9 \%)(P=0.013)$, and the frequency of recovery on the $4^{\text {th }}$ day was significantly higher in the probiotic group than that in the control group $(95.3 \%$ vs. 58.6\%) $(P<0.001)$ [Table 2].

\section{DISCUSSION}

The aim of this study was to investigate the effect of probiotics in the treatment of acute noninflammatory diarrhea in hospitalized children aged 2-10 years. In the present study, the mean frequency and duration of diarrhea were significantly less in the probiotic group than those in the control group. In this regard, a study on investigating the effect of probiotic yeast (Saccharomyces boulardii) on acute diarrhea in children showed that the administration of this yeast after the $2^{\text {nd }}$ day caused a significant reduction in the frequency and duration of diarrhea. Therefore, this treatment can be deemed effective for acute diarrhea in children. ${ }^{[13]}$

In a study by Billoo et al., probiotics caused a significant reduction in the duration and frequency of fecal

Table 1: Mean and standard deviation of diarrhea frequency, duration of diarrhea, duration of fever, and duration of hospital stay in the two studied groups

\begin{tabular}{llcc}
\hline Variable & Group & Mean \pm SD & $P$ \\
\hline Frequency of diarrhea on day 2 & Probiotic & $23.2 \pm 48.7$ & $<0.001$ \\
& Control & $45.2 \pm 09.9$ & \\
Frequency of diarrhea on day 4 & Probiotic & $46.1 \pm 8.2$ & $<0.001$ \\
& Control & $48.2 \pm 71.4$ & \\
Duration of fever (day) & Probiotic & $93.0 \pm 3.2$ & 0.01 \\
& Control & $87.0 \pm 64.2$ & \\
Duration of diarrhea (day) & Probiotic & $11.1 \pm 32.3$ & $<0.001$ \\
& Control & $7.1 \pm 43.4$ & \\
Duration of hospital stay (day) & Probiotic & $54.0 \pm 33.2$ & $<0.001$ \\
& Control & $62.0 \pm 64.2$ & \\
& & & \\
& & &
\end{tabular}

SD: Standard deviation

Table 2: Frequency of anorexia and rate of recovery in patients of two studied groups

\begin{tabular}{lcccc}
\hline Variable & Probiotic & Control & Total & $P$ \\
\hline Dyspepsia, $n(\%)$ & & & & \\
$\quad$ Day 2 & $21(4.24)$ & $27(0.31)$ & $48(7.27)$ & 0.331 \\
$\quad$ Day 4 & $1(2.1)$ & $7(0.8)$ & $8(6.4)$ & 0.064 \\
Recovery rate, $n(\%)$ & & & & \\
$\quad$ Day 2 & $17(8.19)$ & $6(9.6)$ & $23(3.13)$ & 0.013 \\
$\quad$ Day 4 & $82(3.95)$ & $51(6.58)$ & $133(9.76)$ & $<0.001$ \\
\hline
\end{tabular}


excretion without causing any side effects in children aged 2-12 years. ${ }^{[14]}$ In another study by Canani et al. to investigate the effect of probiotics in 571 children with diarrhea in Italy, the mean duration of disease in probiotic-receiving children was $78.5 \mathrm{~h}$ which was shorter than that in the control group (115 h) ${ }^{[15]}$ In another study, the results showed that yogurt alongside L. rhamnosus GG and Bifidobacterium lactis could reduce the duration of antibiotic-induced diarrhea. ${ }^{[16]}$ In a study by Zhao et al., 240 children with Helicobacterpylori infection were studied each in two groups of 120 .

The recovery rate of $H$. pylori infection in one of the groups was $75.8 \%$ (91 out of 120 patients) and in the other group $85 \%$ (102 out of 120 patients), without any significant difference. However, diarrhea during the treatment was significantly less in the probiotic group. Besides, all of the studies are consistent with the results of our study ${ }^{[17]}$ In the present study, the mean durations of fever and hospital stay were significantly less in the probiotic group than those in the control group. While in the study of Grenov et al., the use of probiotics to treat acute diarrhea in children did not affect the length of hospital stay, a significant difference was observed in the duration of diarrhea in outpatient treatment between the two groups. ${ }^{[18]}$

In the study of Grandy which was carried out on children hospitalized for acute diarrhea, the total duration of diarrhea in children given Saccharomyces decreased significantly, and this probiotic could reduce the durations of the disease and the fever by $41.4 \%$ and $73 \%$, respectively. ${ }^{[19]}$ In our study, the mean duration of fever in the probiotic group was significantly lower than that in the control group ( 2.3 vs. 2.64 days). The results of a clinical trial also indicated that synbiotics as a probiotic reduced the duration of fever due to bacillary dysentery in children but did not affect the duration of admission. ${ }^{[20]}$ In another study, similar results were obtained, as the use of probiotic in 1-23-month-old children could reduce the fever caused by Rotavirus, but there was no difference in the duration of hospital stay between the intervention and control groups ${ }^{[19]}$ It can be argued that the type of microorganism causing the disease, and the quality of care performed can affect the course of the treatment and thus the results. There was no significant difference in the incidence of dyspepsia between the patients of the two groups.

In two studies, Ashraf et al. and Shafaghi et al. who investigated the effects of probiotics on Shigella and $H$. pylori observed that these compounds could reduce anorexia and other symptoms. ${ }^{[21,22]}$ On the other hand, the frequency of recovery was significantly higher in the probiotic group than that in the control group. In other studies in this field, the use of probiotics has been reported to increase the rate of recovery in children with diarrhea. ${ }^{[19,23-25]}$ Probiotic treatments can prevent the growth of yeasts and pathogens by inducing changes in the environment and tissue $\mathrm{pH}$ as well as producing antimicrobials, and they can also be effective in the treatment and prevention of the recurrence of their symptoms. ${ }^{[26]}$ Probiotics can also reduce the activity of pathogenic agents by stimulating the local immune system and increasing immunoglobulin $\mathrm{A}$ and mucus trophic activity. ${ }^{[14,27,28]}$ On the other hand, the use of probiotics in patients also has its own particular conditions. For example, their use in immunology compromised patients who may be at increased risk for probiotic sepsis. ${ }^{[8]}$ Bacteremia was also observed in children and adults who had taken probiotics for therapeutic use or by bacteria such as Lactobacillus in several other studies. ${ }^{[29]}$ In addition, milder complications such as bloating, abdominal pain, rash, increased mucus, chest pain, and constipation were also reported by an interventional study. ${ }^{[30]}$ Therefore, necessary precautions should be taken to prevent sepsis and death of children.

\section{CONCLUSION}

Probiotics are effective in the treatment of acute noninflammatory diarrhea in children aged 2-10 years, and they are used as a safe and inexpensive treatment alongside the standard treatment. In future studies, it is necessary to investigate the type of microbes that cause acute diarrhea in order to obtain a clearer picture to generalize and apply the results of the study.

\section{Acknowledgments}

This article was derived from a research project approved by the Research and Technology Deputy of the Shahrekord University of Medical Sciences by number of 2704 in 2017.

Financial support and sponsorship

Nil.

\section{Conflicts of interest}

There are no conflicts of interest.

\section{REFERENCES}

1. World Health Organization. Diarrhoeal Disease. Genoa: World Health Organization; 2017 Available from: http://www.who.int/news-room/ fact-sheets/detail/diarrhoeal-disease. [Last accessed on 2017 May 02].

2. Pawlowski SW, Warren CA, Guerrant R. Diagnosis and treatment of acute or persistent diarrhea. Gastroenterology 2009;136:1874-86.

3. Korpela K, Salonen A, Virta LJ, Kekkonen RA, de Vos WM. Association of early-life antibiotic use and protective effects of breastfeeding: Role of the intestinal microbiota. JAMA Pediatr 2016;170:750-7.

4. Qu M, Lv B, Zhang X, Yan H, Huang Y, Qian H, et al. Prevalence and 
antibiotic resistance of bacterial pathogens isolated from childhood diarrhea in Beijing, China (2010-2014). Gut Pathog 2016;8:31.

5. Guarino A, Lo Vecchio A, Dias JA, Berkley JA, Boey C, Bruzzese D, et al. Universal recommendations for the management of acute diarrhea in nonmalnourished children. J Pediatr Gastroenterol Nutr 2018;67:586-93.

6. Li D, Li Q, Liu C, Lin M, Li X, Xiao X, et al. Efficacy and safety of probiotics in the treatment of Candida-associated stomatitis. Mycoses 2014;57:141-6.

7. Klaenhammer TR. Probiotic bacteria: Today and tomorrow. J Nutr 2000;130:415S-416S.

8. Verna EC, Lucak S. Use of probiotics in gastrointestinal disorders: What to recommend? Ther Adv Gastroenterol 2010;3:307-19.

9. Koenig JE, Spor A, Scalfone N, Fricker AD, Stombaugh J, Knight R, et al. Succession of microbial consortia in the developing infant gut microbiome. Proc Natl Acad Sci U S A. 2011;108 Suppl 1:4578-85.

10. Sharif A, Kheirkhah D, Esfandabadi P, Masoudi S, Ajorpaz N. Comparison of regular and probiotic yogurts in treatment of acute watery diarrhea in children. J Probiotics Health 2017;5:2.

11. Zarinfar N, Sarmadian H, Esmaili A. Effect of probiotic preparation in preventing antibiotic associated diarrhea and colitis: A clinical trial. Iran South Med J 2014;17:368-76.

12. Free TA. Nelson textbook of pediatrics. Nurse Pract 2004;29:31.

13. Sharif MR, Kashani HH, Ardakani AT, Kheirkhah D, Tabatabaei F, Sharif A. The effect of a yeast probiotic on acute diarrhea in children. Probiotics Antimicrob Proteins. 2016;8:211-4.

14. Billoo AG, Memon MA, Khaskheli SA, Murtaza G, Iqbal K, Saeed Shekhani M, et al. Role of a probiotic (Saccharomyces boulardii) in management and prevention of diarrhoea. World J Gastroenterol 2006;12:4557-60.

15. Canani RB, Cirillo P, Terrin G, Cesarano L, Spagnuolo MI, De Vincenzo A, et al. Probiotics for treatment of acute diarrhoea in children: Randomised clinical trial of five different preparations. BMJ 2007;335:340.

16. Fox MJ, Ahuja KD, Robertson IK, Ball MJ, Eri RD. Can probiotic yogurt prevent diarrhoea in children on antibiotics? A double-blind, randomised, placebo-controlled study. BMJ Open 2015;5:e006474.

17. Zhao HM, Ou-Yang HJ, Duan BP, Xu B, Chen ZY, Tang J, et al. Clinical effect of triple therapy combined with Saccharomyces boulardii in the treatment of Helicobacter pylori infection in children. Zhongguo Dang Dai Er Ke Za Zhi 2014;16:230-3.

18. Grenov B, Namusoke H, Lanyero B, Nabukeera-Barungi N, Ritz C, Molgaard C, et al. Effect of probiotics on diarrhea in children with severe acute malnutrition: A randomized controlled study in Uganda. J Pediatr Gastroenterol Nutr 2017;64:396-403.

19. Grandy G, Medina M, Soria R, Terán CG, Araya M. Probiotics in the treatment of acute Rotavirus diarrhoea. A randomized, double-blind, controlled trial using two different probiotic preparations in Bolivian children. BMC Infect Dis 2010;10:253.

20. Kahbazi M, Ebrahimi M, Zarinfar N, Arjomandzadegan M, Fereydouni T, Karimi F, et al. Efficacy of synbiotics for treatment of bacillary dysentery in children: A double-blind, randomized, placebo-controlled study. Adv Med 2016;2016:3194010.

21. Ashraf H, Mahalanabis D, Mitra AK, Tzipori S, Fuchs GJ. Hyperimmune bovine colostrum in the treatment of shigellosis in children: A double-blind, randomized, controlled trial. Acta Paediatr 2001;90:1373-8.

22. Shafaghi A, Pourkazemi A, Khosravani M, Fakhrie Asl S, Amir Maafi A, Atrkar Roshan Z, et al. The effect of probiotic plus prebiotic supplementation on the tolerance and efficacy of Helicobacter pylori eradication quadruple therapy: A randomized prospective double blind controlled trial. Middle East J Dig Dis 2016;8:179-88.

23. Erdoğan O, Tanyeri B, Torun E, Gönüllü E, Arslan H, Erenberk U, et al. The comparition of the efficacy of two different probiotics in rotavirus gastroenteritis in children. J Trop Med 2012;2012:787240.

24. Francavilla R, Lionetti E, Castellaneta S, Ciruzzi F, Indrio F, Masciale A, et al. Randomised clinical trial: Lactobacillus reuteri DSM 17938 vs. placebo in children with acute diarrhea - A double-blind study. Aliment Pharmacol Ther 2012;36:363-9.

25. Rerksuppaphol S, Rerksuppaphol L. Lactobacillus acidophilus and Bifidobacterium bifidum stored at ambient temperature are effective in the treatment of acute diarrhoea. Ann Trop Paediatr 2010;30:299-304.

26. Cribby S, Taylor M, Reid G. Vaginal microbiota and the use of probiotics. Interdiscip Perspect Infect Dis 2008;2008:256490.

27. O'Hanlon DE, Moench TR, Cone RA. Vaginal $\mathrm{pH}$ and microbicidal lactic acid when lactobacilli dominate the microbiota. PLoS One. 2013;8:e80074.

28. Aroutcheva A, Gariti D, Simon M, Shott S, Faro J, Simoes JA, et al. Defense factors of vaginal lactobacilli. Am J Obstet Gynecol 2001;185:375-9.

29. Cherifi S, Robberecht J, Miendje Y. Saccharomyces cerevisiae fungemia in an elderly patient with Clostridium difficile colitis. Acta Clin Belg 2004;59:223-4.

30. Hayes SR, Vargas AJ. Probiotics for the prevention of pediatric antibiotic-associated diarrhea. Explore (NY) 2016;12:463-6. 